\title{
Synthesis and Characterization of Polysulfone/ POSS Hybrid Networks by Photoinduced Crosslinking Polymerization
}

\author{
Cemil Dizman, Tamer Uyar, Mehmet Atilla Tasdelen,* Yusuf Yagci*
}

Crosslinked polysulfone/polyhedral oligomeric silsesquioxane (POSS) hybrid networks were synthesized in this work by photoinduced copolymerization of polysulfone dimethacrylate (PSU-DMA) and multifunctional POSS-methacrylamide (POSS-MAAm) with various feed ratios. The morphology of the nanocomposites was investigated by transmission electron microscopy (TEM), which suggests the random dispersion of POSS in the PSU matrix without macroscopic agglomeration. Thermogravimetric analysis results confirmed that the thermal stability and char yield of PSU-DMA/POSSMAAm nanocomposites increased with the increase of POSS loading. Enhanced glass transition temperatures and storage modulus of the networks were observed to be higher than its precursor polymer.

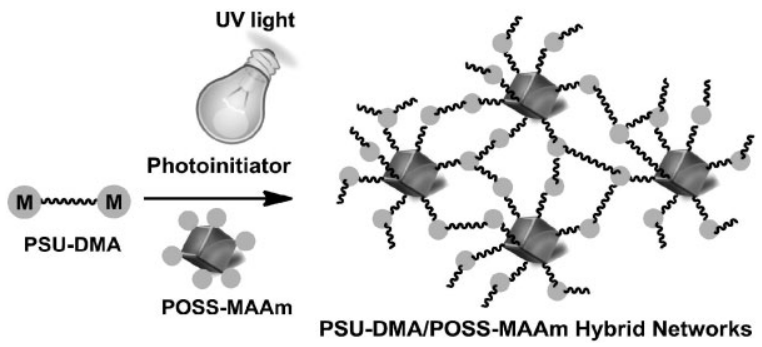

C. Dizman

Department of Chemistry, Istanbul Technical University, Maslak, Istanbul 34469, Turkey

C. Dizman

Chemistry Institute, TUBITAK Marmara Research Center, Gebze, Kocaeli 41470, Turkey

Dr. T. Uyar

UNAM-Institute of Materials Science and Nanotechnology,

Bilkent University, 06800 Ankara, Turkey

Dr. M. A. Tasdelen

Faculty of Engineering, Department of Polymer Engineering,

Yalova University, TR-7710o Yalova, Turkey

E-mail: tasdelen@yalova.edu.tr

Prof. Y. Yagci

Department of Chemistry, Istanbul Technical University, Maslak, Istanbul 34469, Turkey

E-mail: yusuf@itu.edu.tr

Prof. Y. Yagci

Faculty of Science, Chemistry Department, King Abdulaziz

University, Jeddah, Saudi Arabia

\section{Introduction}

Polysulfone (PSU) is an amorphous engineering thermoplastic with exceptional thermal, mechanical, and chemical properties such as thermal stability, mechanical strength, stiffness, high rigidity, excellent resistance to hydrolysis, and acids and bases, oxidative resistance, resistance to creep, and has an extensive operative range of temperature and $\mathrm{pH}^{[1-3]}$ PSUs are often modified by chemical or physical means to tailor their properties for use in some specialized processes. These include: (i) using functional co-monomers during polycondensation, ${ }^{[4-7]}$ (ii) postsynthesis modification processes, ${ }^{[8-16]}$ and (iii) synthesis of PSU-based composites. ${ }^{[17-25]}$ Hybrid inorganic-organic materials based on incorporation of nano-sized inorganic particles into polymer matrices have gained considerable attention due to their markedly superior mechanical and thermal properties. ${ }^{[26-28]}$ Nanostructured fillers have dimensions typically ranging from 1 to $100 \mathrm{~nm}$. Based on the nanoscale dimension, they are classified as one-dimensional 
(clays and graphites), ${ }^{[29-35]}$ two-dimensional (nanofibers, nanotubes, or whiskers $)^{[36-38]}$, and three-dimensional (spherical silica, metal particles, and semiconductor nanoclusters). ${ }^{[39-46]}$ Polyhedral oligomeric silsesquioxanes (POSS) are three-dimensional oligomeric, organosilicon compounds with cage frameworks surrounded by functional groups on the periphery. In addition to their welldefined nanostructures, high compatibility with polymers, and the commercial availability of various useful precursors, POSS derivatives impart excellent thermal and mechanical properties to polymer nanocomposites. ${ }^{[4-49]}$

Unlike other nano-sized materials including carbon nanotubes, clays, and zeolites, a dispersion problem is not associated with POSS molecules due to their solubility in common organic solvents. ${ }^{[50-52]}$ POSS has been successfully incorporated into various polymers such as polyolefins, ${ }^{[53-56]}$ polynorbornenes, ${ }^{[57]}$ polystyrenes, ${ }^{[58-60]}$ poly(meth)acrylates, ${ }^{[61-67]}$ polysiloxanes, ${ }^{[68-71]}$ epoxies, ${ }^{[72-75]}$ polyurethanes, ${ }^{[76-80]}$ polyimides ${ }^{[81,82]}$ etc. However, to our knowledge, there has not been a report of the preparation of POSS-containing PSU networks in the literature.

In this study, we report the first synthesis of a POSS macromonomer bearing multi-functional methacrylamides by amidation of POSS-amine with methacryloyl chloride. The subsequent photoinduced crosslinking polymerization of this macromonomer with PSU dimethacryltate leads to the one-pot preparation of a series of hybrid networks. The effects of POSS nanoparticles on the properties of the hybrid networks, such as thermal and morphological properties have been systematically investigated using techniques including transmission electron microscopy (TEM), differential scanning calorimetry, and thermogravimetric analysis.

\section{Experimental Section}

\subsection{Materials}

Tetrahydrofuran (THF, 99\%, Fluka) was dried and distilled over benzophenone/sodium metal. Bisphenol $\mathrm{A}$ and bis( $p$-chlorophenyl) sulfone (Hallochem Pharma Co. Ltd, China), methanol (Merck), dimethyl acetamide (DMAC, 99\%, Merck), and triethylamine (TEA, Aldrich, HPLC grade), dichloromethane (99\%, Aldrich), chloroform (+99\%, Aldrich), methacryloyl chloride (+97\%, Merck), 2,2-dimethoxy-2-phenylacetophenone (DMPA, 99\%, Acros) were used without any additional treatment. PSU dimethacrylate (PSUDMA) macromonomer has been synthesized by condensation polymerization and subsequent esterification processes according to the published method. ${ }^{[83]}$

\subsection{Synthesis of POSS-Methacrylamide (POSS-MAAm)}

Octa (aminophenyl) silsesquioxane was synthesized according to the literature reported by Ak et al. ${ }^{[84]}\left({ }^{1} \mathrm{H}\right.$ NMR in DMSO- $d_{6}$ : 7.9-6.1
(Ar, 4.0H) and 5.5-4.4 (-NH, 2.0H); Fourier transform infrared (FT-IR) $\left(\mathrm{cm}^{-1}\right)$ : $3368(\nu \mathrm{N}-\mathrm{H}$ asym.), $3456(\nu \mathrm{N}-\mathrm{H}$ sym.) and 1304-990 (vSiO-Si)). POSS-amine $(0.2 \mathrm{~g}, 0.17 \mathrm{mmol})$ and triethylamine $(0.19 \mathrm{~mL}$, $1.39 \mathrm{mmol}$ ) were added in dry THF $(20 \mathrm{~mL})$ and cooled to $0{ }^{\circ} \mathrm{C}$. Excess amount of methacryloyl chloride $(0.28 \mathrm{~mL}, 3.47 \mathrm{mmol})$ was added dropwise while stirring. The reaction mixture was allowed to heat up to room temperature and stirred for $24 \mathrm{~h}$. After removing the solvent by rotary evaporation, POSSmethacrylamide was extracted by ethyl acetate using a separation funnel. POSS-MAAm was obtained by rotaevaporation of ethyl acetate.

\subsection{Preparation of the PSU/POSS Nanocomposites}

POSS-MAAm (1, 5, and 10\% of the monomer by weight) and DMPA (1\% of the oligomer by weight) were mixed with PSU-DMA oligomer dissolved in dry THF in tubes via a magnetic stirrer at room temperature for $2 \mathrm{~h}$ in a dark place. Then, the mixed solutions were poured into petri dishes and set apart for the removal of the solvent at room temperature in a dark place. Then, UV irradiation was applied for about $4 \mathrm{~h}$ for the preparation of the hybrid networks.

\subsection{Characterization}

FT-IR spectra were recorded on a Perkin-Elmer FT-IR Spectrum One B spectrometer. ${ }^{1} \mathrm{H}$ NMR spectra of $5-10 \% \mathrm{w} / \mathrm{w}$ solutions of the intermediates and final polymers in $\mathrm{CDCl}_{3}$ with $\mathrm{Si}\left(\mathrm{CH}_{3}\right)_{4}$ as an internal standard were recorded at room temperature at $250 \mathrm{MHz}$ on a Bruker DPX 250 spectrometer. Differential scanning calorimetry (DSC) was performed on a Perkin-Elmer Diamond DSC with a heating rate of $10^{\circ} \mathrm{C}$ min under nitrogen flow. Thermal gravimetric analysis (TGA) was performed on Perkin-Elmer Diamond TA/TGA with a heating rate of $10^{\circ} \mathrm{C}$ min under nitrogen flow. TEM imaging of the samples was carried out by FEI Tecnai G2 F30 instrument operating at an acceleration voltage of $300 \mathrm{kV}$. About $100 \mathrm{~nm}$ ultrathin TEM specimens were cut by using cryo-ultramicrotome (EMUC6 + EMFC6, Leica) equipped with a diamond knife. The ultrathin samples were placed on copper grids for TEM analyses. Dynamic mechanic analysis (DMA) was performed on a ExStar 6100 , SII Nanotechnology operating in the tension mode at an oscillation frequency of $1 \mathrm{~Hz}$. Data were collected from room temperature to $300^{\circ} \mathrm{C}$ at a scanning rate of $3^{\circ} \mathrm{C} \cdot \mathrm{min}^{-1}$. The sample specimens were cut into rectangular bars, $1 \mathrm{~mm} \times 20 \mathrm{~mm} \times$ $10 \mathrm{~mm}$.

\section{Results and Discussion}

The POSS methacrylamide (POSS-MAAm) was prepared by the amidation reaction of POSS-amine with methacryloyl chloride. The chemical structure of POSS-MAAm was confirmed by FT-IR and ${ }^{1} \mathrm{H}$ NMR analysis. FT-IR spectrum showed new peaks at 1660 and $1620 \mathrm{~cm}^{-1}$ for amide carbonyl and carbon-carbon double bonds, respectively (Figure 1). Moreover, disappearance of symmetric and 


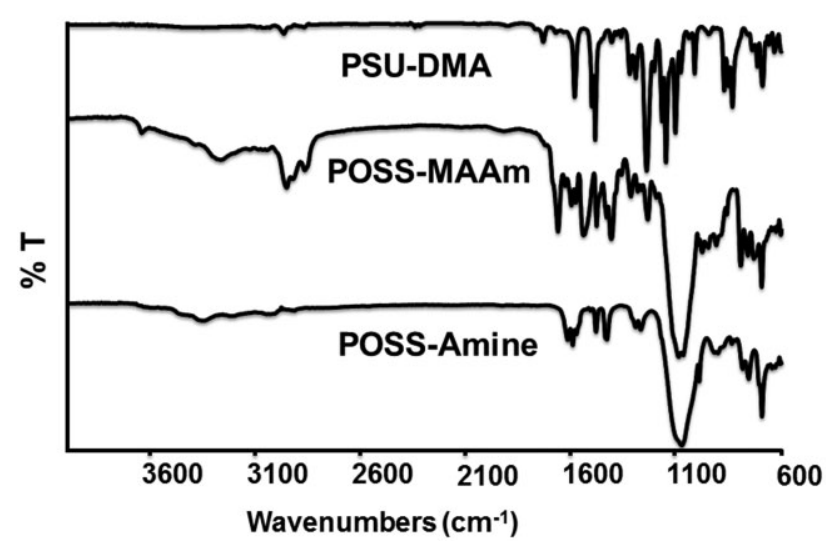

Figure 1. FT-IR spectra of neat polysulfone dimethacrylate (PSUDMA), POSS-amine and POSS-methacrylamide (POSS-MAAm).

asymmetric $\nu \mathrm{N}-\mathrm{H}$ peaks at 3368 and $3456 \mathrm{~cm}^{-1}$ and appearance of a new broad peak near the $3265 \mathrm{~cm}^{-1}$ confirmed that a complete transformation of amine to amide group. Also, a strong absorption band appeared in the FTIR spectra in the range 990 and $1190 \mathrm{~cm}^{-1}$ assigned to the asymmetric stretching vibration of $v \mathrm{Si}-\mathrm{O}-\mathrm{Si}$ groups, indicating the precence of POSS.

Figure 2 shows ${ }^{1} \mathrm{H}$ NMR spectra obtained for POSS amine and the corresponding POSS-methacrylamide macromonomer. The efficient transformation of amine to amide was evidenced by complete disappearance of amine protons (a) at 5.0 ppm and appearance of new amide protons (b) and vinyl protons (c) at 9.8 and $5.9 \mathrm{ppm}$, respectively. Moreover, the aromatic peaks of POSS were also shifted at higher magnetic fields in the range of 6.7-7.5 ppm. These results confirmed that the successful incorporation of methacrylamide into POSS. PSU-DMA macromonomer was synthesized by condensation polymerization between bisphenol A

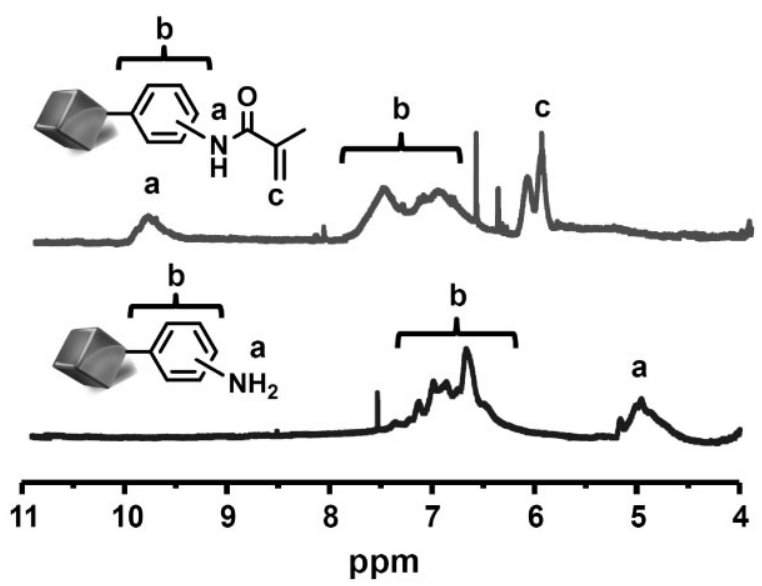

Figure 2. 'H NMR spectra of POSS-amine and POSS-methacrylamide in DMSO- $d_{6}$. and bis( $p$-chlorophenyl) sulfone, and subsequent esterification process and detailed chemical characterization has given in the literature. ${ }^{[83]}$

Our concept is based on the incorporation of polymerizable groups on both POSS-MAAm and PSU-DMA which provides chemical linking of the diverse molecules. For this purpose, POSS-MAAm, PSU-DMA macromonomer, and 2-2dimethoxy-2-phenylacetophenone (DMPA) photoinitiator were mixed in tetrahydrofuran (Scheme 1). Photochemically generated radicals were utilized as reactive species for the formation of chemical crosslinks in an organicinorganic-organic hybrid network. The same amount of photoinitiator was used in all formulations in order to keep photopolymerization conditions identical.

Thermal stability of the photocured hybrid networks was investigated by TGA under nitrogen atmosphere and (Figure 3). According the TGA results, decomposition temperatures and char yields of PSU-DMA/POSS-MAAm nanocomposites were higher than that of pristine PSUDMA under nitrogen atmosphere. The char yield was improved considerably from $18.8 \%$ for PSU-DMA to $37.6 \%$ for PSU-DMA/POSS-MAAm- 10 at $700^{\circ} \mathrm{C}$. A plausible explanation for these results is that the multi-functional POSS fillers not only increase the cross-linking densities that hinder the segmental motion of the polymer chains and retarded diffusion of gaseous fragment product, but also increase the inorganic content in the nanocomposites. ${ }^{[85]}$

The effect of POSS content on the glass transtion temperature of PSU was also investigated by DSC under
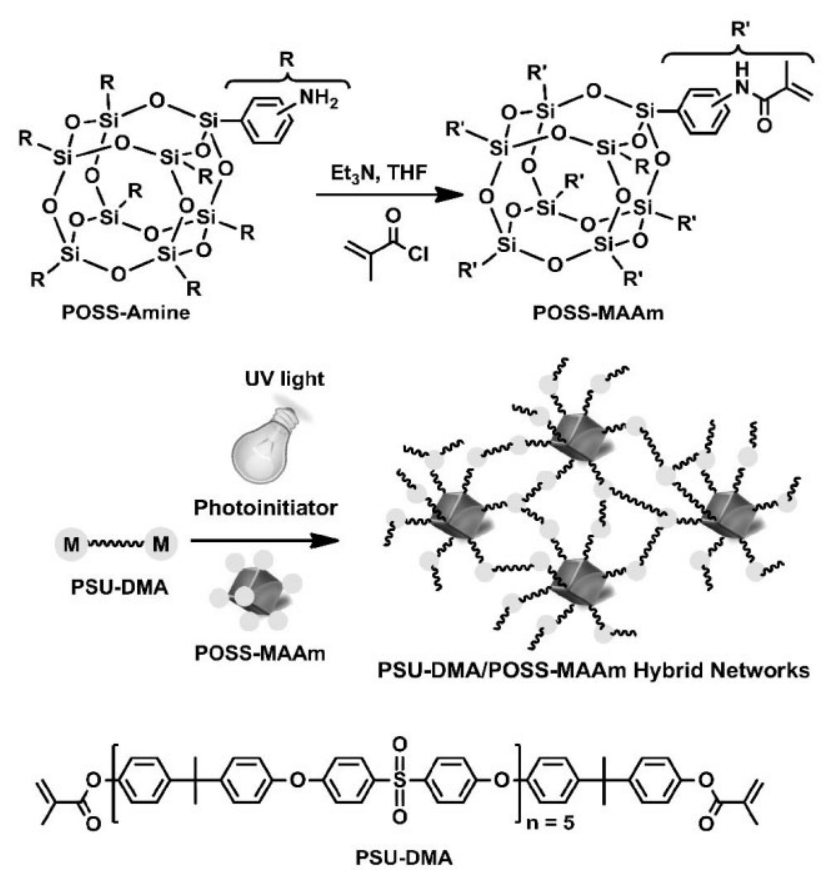

Scheme 1. Preparation of PSU/POSS hybrid networks by photoinitiated cross-linking polymerization.

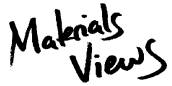

www.MaterialsViews.com 


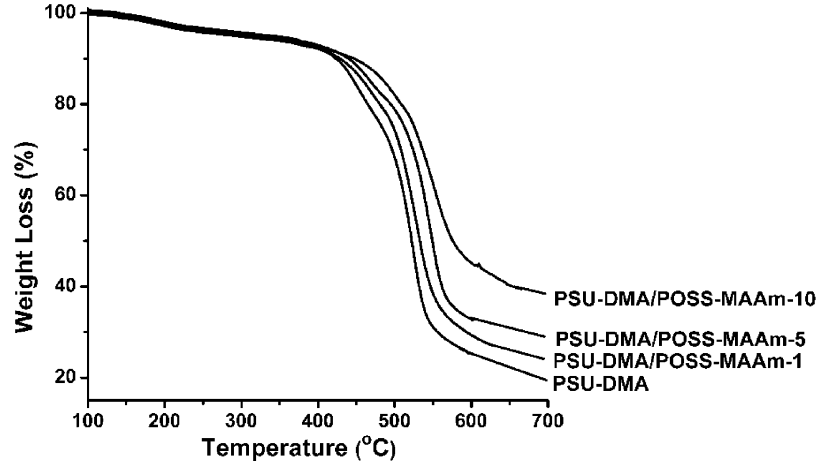

Figure 3. TGA thermograms of neat PSU-DMA and resulting hybrid networks containing 1, 5 and $10 \%$ POSS.

nitrogen atmosphere (Figure 4). All DSC thermograms displayed single glass transition temperatures $\left(T_{\mathrm{g}}\right)$. Notably, the $T_{\mathrm{g}}$ of precursor PSU oligomer was observed at $136^{\circ} \mathrm{C}$. With the addition of the POSS to the polymer matrix, $T_{\mathrm{g}} \mathrm{S}$ of the PSU-DMA/POSS-MAAm were 180,187 , and $189^{\circ} \mathrm{C}$, respectively. ${ }^{\left[{ }^{86]}\right.}$ From the DSC results it can be seen that the crosslinking and incorporation of the POSS resulted in an increase in the $T_{\mathrm{g}}$ relative to virgin PSU-DMA, as summarized in Table 1. Apparently, due to the presence of polymerizable groups, the PSU-DMA matrix is crosslinked by itself. However, addition of octa-unsaturated POSSMAAm molecules results in co-crosslinking through the double bonds present in the components. Thus, both crosslinking and POSS addition contribute to the increase in the observed $T_{\mathrm{g}}$. It was previously reported that the crosslinked PSU exhibits much higher $T_{\mathrm{g}}$ than that of its precursor polymer. ${ }^{[83]}$ Further increase in the amount of POSS seemingly results in some but slight increase in $T_{\mathrm{g}}$.

The morphology of resulting hybrid networks was further characterized by means of transmission electron microscopoy (TEM). As represented, the PSU-DMA/POSSMAAm-10 nanocomposite was chosen to analyze the distributions of nanoparticles in the networks. Figure 5 represented the TEM micrographs of PSU-DMA/POSSMAAm-10, it could be seen that considerable amounts of

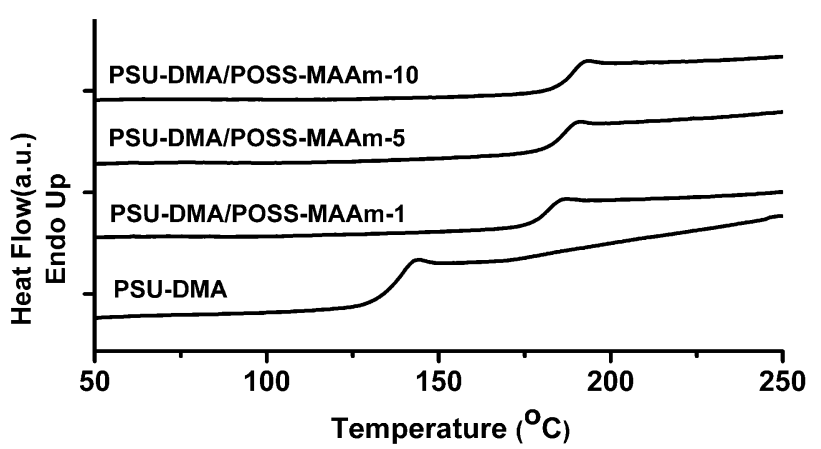

Figure 4. DSC traces of neat PSU-DMA and resulting hybrid networks containing 1,5 and $10 \%$ POSS-MAAm.

dark spherical particles uniformly dispersed in the networks. These dark particles could be attributed to POSS nanoparticles because of the high electron density of the POSS nanocages. ${ }^{[87]}$ Moreover, with higher magnification (Figure 5B), spherical POSS nanoparticles with a diameter ranging from 1.5 to $3 \mathrm{~nm}$ were clearly observed, which was close to the dimensions of a single POSS molecule. Evidently, these results demonstrated that POSS cages were homogeneously distributed in polymer matrix at the nanometer scale.

The values of $E$ (Young's modulus) and $\tan \delta$ from the dynamic mechanical analysis study of cured PSU-DMA/ POSS-MAAm-10 and PSU-DMA (pure resin) samples are shown in Figures 6 and 7. The addition of $10 \mathrm{wt} \%$ of POSSMAAm was found to result in a considerable increase of the Young's modulus (Figure 6). In the temperature region from 30 to $80^{\circ} \mathrm{C}$, the Young's modulus of the sample PSU/POSS-10 was about two times greater than that of PSU-DMA. As the temperature incresead, the gap between the Young's moduli of the samples PSU/POSS-10 and PSU-DMA decreased. The position of a peak maximum in the $\tan \delta$ versus temperature curve can be related to the glass transition temperature. It was seen that the addition of 10 wt\% POSS-MAAm shifted $T_{\mathrm{g}}$ of PSU towards a higher value by about $25^{\circ} \mathrm{C}$ (Figure 7 ). This result suggested that

Table 1. Thermal properties of neat PSU-DMA and PSU-DMA/POSS-MAAm hybrid networks.

\begin{tabular}{|c|c|c|c|c|c|}
\hline \multirow[t]{2}{*}{ Sample } & \multirow[t]{2}{*}{ POSS[wt\%] } & \multirow[t]{2}{*}{$T_{\mathrm{g}}{ }^{\mathrm{a})}\left[{ }^{\circ} \mathrm{C}\right]$} & \multicolumn{2}{|c|}{ Weight loss temperature ${ }^{b}$} & \multirow{2}{*}{$\begin{array}{c}\text { Char } \\
\text { yield }^{\text {b) }}[\%]\end{array}$} \\
\hline & & & $20 \mathrm{wt} \%\left[{ }^{\circ} \mathrm{C}\right]$ & $60 \mathrm{wt} \%\left[{ }^{\circ} \mathrm{C}\right]$ & \\
\hline PSU-DMA & - & 137 & 464.8 & 531.9 & 18.8 \\
\hline PSU-DMA/POSS-MAAm-1 & 1 & 180 & 480.6 & 546.7 & 23.6 \\
\hline PSU-DMA/POSS-MAAm-5 & 5 & 187 & 494.8 & 561.6 & 28.8 \\
\hline PSU-DMA/POSS-MAAm-10 & 10 & 189 & 508.5 & 653.8 & 37.6 \\
\hline
\end{tabular}

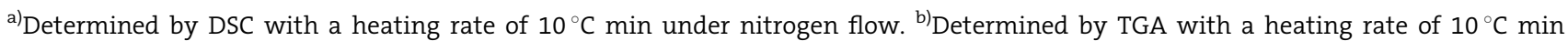
under nitrogen flow. 

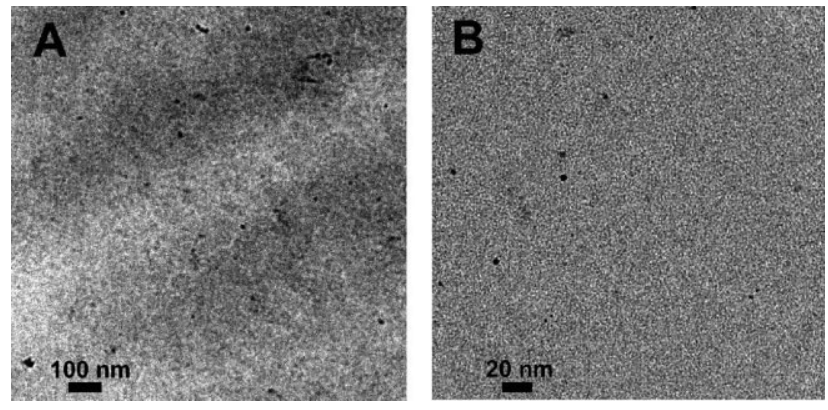

Figure 5. TEM micrographs of PSU-DMA/POSS-MAAm-10 hybrid network in low (A, scale bar: $100 \mathrm{~nm})$ and high (A, scale bar: $20 \mathrm{~nm}$ ) magnification.

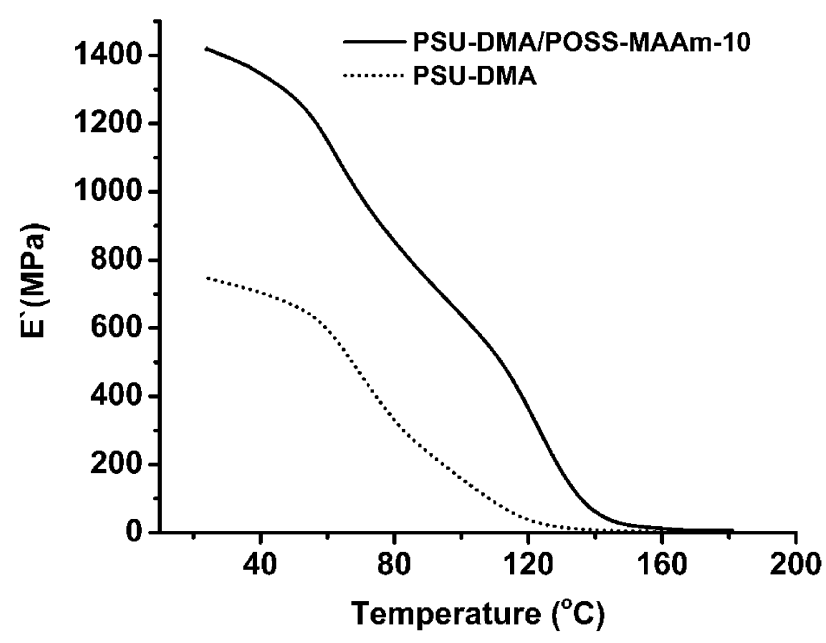

Figure 6. Storage modulus versus temperature plots of PSU-DMA and PSU-DMA/POSS-MAAm-10 hybrid network.

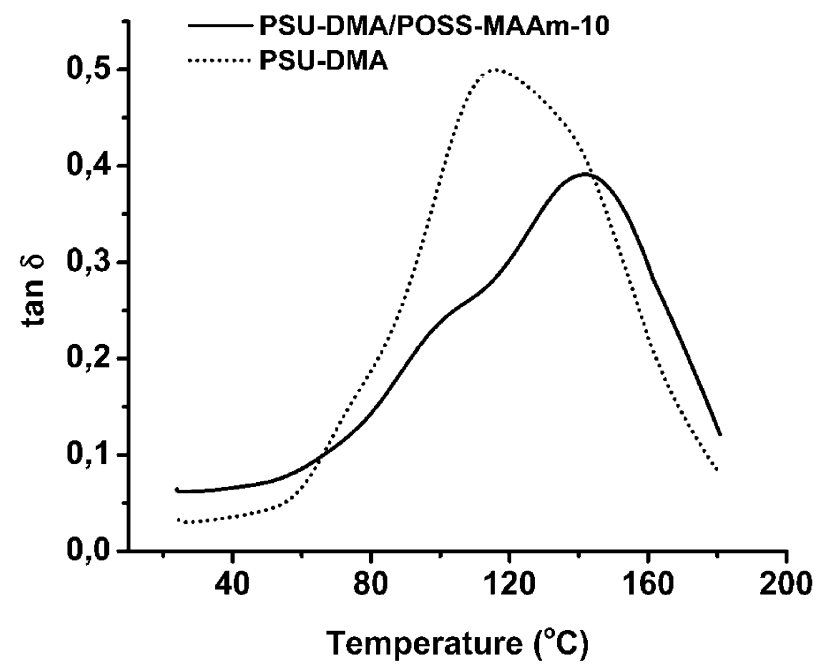

Figure 7. Loss factor versus temperature plots of PSU-DMA and PSU-DMA/POSS-MAAm-10 hybrid network. the presence of POSS molecules resulted in a decrease of molecular mobility in PSU either due to the induced constrains of the PSU chains, or due to enhanced van der Waals bonding forces between POSS and the PSU chains. In other words, the POSS nanostructures exhibited some physical interactions with the PSU polymer chains. Similar behavior was also observed in structurally different POSS/polymer nanocomposites. ${ }^{[88-90]}$

\section{Conclusion}

Conclusively, a series of novel inorganic-organic network hybrids was successfully prepared by photoinduced crosslinking polymerization of PSU dimethacrylate and multifunctional POSS-methacrylamide. The good compability of methacrylate and methacrylamide groups provided homogenous crosslinking reaction to form hybrid network. Thermal analysis showed improved thermal stability with higher glass transition and degradation temperatures and char yields, demonstrating that the inclusion of the inorganic POSS nanoparticles makes the organic polymer matrix more thermally robust. The remarkable increase of the thermal properties of is mainly due to high-crosslink density and three-dimensional network structure. The TEM analysis confirms nanoscale dispersion of POSS cages in the PSU networks. The storage modulus of the network was observed to be somewhat higher than that of the precursor polymer. Thus, these hybrid networks can be used as an advanced composite material in membrane technology for better performances.

Acknowledgements: The authors thank the State Planning Organization of Turkey (DPT, Project no: 2005K120920) and Yalova University Research Fund (Project no: 2011/021) for the financial support. The authors thank Istanbul Technical University, the State Planning Organization of Turkey (DPT, Project no: 2005K120920) and Yalova University Research Fund (Project no: 2011/021) for the financial support. M.A.T. is also indebted to the FABED Foundation for financial support of this work.

Received: September 20, 2012; Revised: October 8, 2012; Published online: December 19, 2012; DOI: 10.1002/mame.201200351

Keywords: crosslinking; high-performance polymers; nanocomposites; photopolymerizations; polyhedral oligomeric silsesquioxane (POSS); polysulfone

[1] F. Wang, M. Hickner, Y. S. Kim, T. A. Zawodzinski, J. E. McGrath, J. Membr. Sci. 2002, 197, 231.

[2] M. A. Hickner, H. Ghassemi, Y. S. Kim, B. R. Einsla, J. E. McGrath, Chem. Rev. 2004, 104, 4587.

[3] M. D. Guiver, G. P. Robertson, M. Yoshikawa, C. M. Tam, "Functionalized polysulfones: Methods for chemical modification and membrane applications", in Membrane Formation

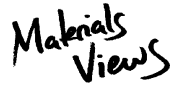

www.MaterialsViews.com 
and Modification, I. Pinnau B. D. Freeman, Eds., ACS Symposium Series, American Chemical Society, Washington DC 2000, p. 137.

[4] J. Jouanneau, R. Mercier, L. Gonon, G. Gebel, Macromolecules 2007, 40, 983.

[5] H. R. Kricheldorf, L. Vakhtangishvili, D. Fritsch, J. Polym. Sci. Pol. Chem. 2002, 40, 2967.

[6] T. Koch, H. Ritter, Macromol. Chem. Phys. 1994, 195, 1709.

[7] C. G. Herbert, H. Ghassemi, A. S. Hay, J. Polym. Sci. Pol. Chem. 1997, 35, 1095.

[8] M. D. Guiver, G. P. Robertson, S. Foley, Macromolecules 1995, 28, 7612.

[9] H. Toiserkani, G. Yilmaz, Y. Yagci, L. Torun, Macromol. Chem. Phys. 2010, 211, 2389.

[10] C. Dizman, D. O. Demirkol, S. Ates, L. Torun, S. Sakarya, S. Timur, Y. Yagci, Colloids Surf. B 2011, 88, 265.

[11] M. Karadag, G. Yilmaz, H. Toiserkani, D. O. Demirkol, S. Sakarya, L. Torun, S. Timur, Y. Yagci, Macromol. Biosci. 2011, 11, 1235.

[12] G. Yilmaz, H. Toiserkani, D. O. Demirkol, S. Sakarya, S. Timur, L. Torun, Y. Yagci, Mater. Sci. Eng. C 2011, 31, 1091.

[13] S. Ates, C. Dizman, B. Aydogan, B. Kiskan, L. Torun, Y. Yagci, Polymer 2011, 52, 1504.

[14] G. Yilmaz, H. Toiserkani, D. O. Demirkol, S. Sakarya, S. Timur, Y. Yagci, L. Torun, J. Polym. Sci. Pol. Chem. 2011, 49, 110.

[15] B. Van der Bruggen, J. Appl. Polym. Sci. 2009, 114, 630.

[16] L. Breitbach, E. Hinke, E. Staude, Angew. Makromol. Chem. 1991, 184, 183.

[17] C. Dizman, S. Ates, T. Uyar, M. A. Tasdelen, L. Torun, Y. Yagci, Macromol. Mater. Eng. 2011, 296, 1101.

[18] M. Sangermano, I. Roppolo, V. H. A. Camara, C. Dizman, S. Ates, L. Torun, Y. Yagci, Macromol. Mater. Eng. 2011, 296, 820.

[19] G. S. Sur, H. L. Sun, S. G. Lyu, J. E. Mark, Polymer 2001, 42, 9783.

[20] S. Kim, L. Chen, J. K. Johnson, E. Marand, J. Membr. Sci. 2007, 294, 147

[21] J. Y. Ahn, W. J. Chung, I. Pinnau, M. D. Guiver, J. Membr. Sci. 2008, 314, 123.

[22] F. M. Uhl, S. P. Davuluri, S. C. Wong, D. C. Webster, Chem. Mater. 2004, 16, 1135.

[23] Y. N. Yang, P. Wang, Polymer 2006, 47, 2683.

[24] J. S. Taurozzi, H. Arul, V. Z. Bosak, A. F. Burban, T. C. Voice, M. L. Bruening, V. V. Tarabara, J. Membr. Sci. 2008, 325, 58.

[25] G. L. Jadav, P. S. Singh, J. Membr. Sci. 2009, 328, 257.

[26] C. Sanchez, G. Soler-Illia, F. Ribot, T. Lalot, C. R. Mayer, V. Cabuil, Chem. Mater. 2001, 13, 3061.

[27] C. Sanchez, B. Julian, P. Belleville, M. Popall, J. Mater. Chem. 2005, 15, 3559.

[28] M-a. Kakimoto, A. Takahashi, T-a. Tsurumi, J. Hao, L. Li, R. Kikuchi, T. Miwa, T. Oono, S. Yamada, Mater. Sci. Eng. B 2006, 132, 74

[29] A. Nese, S. Sen, M. A. Tasdelen, N. Nugay, Y. Yagci, Macromol. Chem. Phys. 2006, 207, 820.

[30] H. Akat, M. A. Tasdelen, F. Du Prez, Y. Yagci, Eur. Polym. J. 2008, 44, 1949

[31] A. Oral, M. A. Tasdelen, A. L. Demirel, Y. Yagci, Polymer 2009, 50,3905

[32] A. Oral, M. A. Tasdelen, A. L. Demirel, Y. Yagci, J. Polym. Sci. Pol. Chem. 2009, 47, 5328.

[33] Z. Yenice, M. A. Tasdelen, A. Oral, C. Guler, Y. Yagci, J. Polym. Sci. Pol. Chem. 2009, 47, 2190.

[34] M. A. Tasdelen, J. Kreutzer, Y. Yagci, Macromol. Chem. Phys. 2010, 211, 279.
[35] K. D. Demir, M. A. Tasdelen, T. Uyar, A. W. Kawaguchi, A. Sudo, T. Endo, Y. Yagci, J. Polym. Sci. Pol. Chem. 2011, 49, 4213.

[36] M. Moniruzzaman, K. I. Winey, Macromolecules 2006, 39, 5194.

[37] J. N. Coleman, U. Khan, Y. K. Gun'ko, Adv. Mater. 2006, 18, 689.

[38] F. M. Du, R. C. Scogna, W. Zhou, S. Brand, J. E. Fischer, K. I. Winey, Macromolecules 2004, 37, 9048.

[39] M. Sangermano, Y. Yagci, G. Rizza, Macromolecules 2007, 40, 8827.

[40] Y. Yagci, M. Sangermano, G. Rizza, Macromolecules 2008, 41, 7268.

[41] Y. Yagci, M. Sangermano, G. Rizza, Chem. Commun. 2008, 2771.

[42] Y. Yagci, M. Sangermano, G. Rizza, Polymer 2008, 49, 5195.

[43] O. Eksik, A. T. Erciyes, Y. Yagci, J. Macromol. Sci., Pure Appl. Chem. 2008, 45, 698.

[44] M. Uygun, M. U. Kahveci, D. Odaci, S. Timur, Y. Yagci, Macromol. Chem. Phys. 2009, 210, 1867.

[45] Y. Y. Durmaz, M. Sangermano, Y. Yagci, J. Polym. Sci. Pol. Chem. 2010, 48, 2862

[46] O. Eksik, M. A. Tasdelen, A. T. Erciyes, Y. Yagci, Compos. Interfaces 2010, 17, 357.

[47] D. B. Cordes, P. D. Lickiss, F. Rataboul, Chem. Rev. 2010, 110, 2081.

[48] S. W. Kuo, F. C. Chang, Prog. Polym. Sci. 2011, 36, 1649.

[49] G. Z. Li, L. C. Wang, H. L. Ni, C. U. Pittman, J. Inorg. Organomet. Polym. 2001, 11, 123.

[50] V. Ervithayasuporn, X. Wang, B. Gacal, B. N. Gacal, Y. Yagci, Y. Kawakami, J. Organomet. Chem. 2011, 696, 2193.

[51] V. Ervithayasuporn, T. Tomeechai, N. Takeda, M. Unno, A. Chaiyanurakkul, R. Hamkool, T. Osotchan, Organometallics 2011, 30, 4475.

[52] Y. Kawakami, React. Funct. Polym. 2007, 67, 1137.

[53] L. Zheng, R. J. Farris, E. B. Coughlin, Macromolecules 2001, 34, 8034.

[54] L. Zheng, R. J. Farris, E. B. Coughlin, J. Polym. Sci. Pol. Chem. 2001, 39, 2920.

[55] A. Tsuchida, C. Bolln, F. G. Sernetz, H. Frey, R. Mulhaupt, Macromolecules 1997, 30, 2818.

[56] A. Fina, D. Tabuani, A. Frache, G. Camino, Polymer 2005, 46, 7855.

[57] G. S. Constable, A. J. Lesser, E. B. Coughlin, Macromolecules 2004, 37, 1276.

[58] L. Zheng, R. M. Kasi, R. J. Farris, E. B. Coughlin, J. Polym. Sci. Pol. Chem. 2002, 40, 885.

[59] G. Cardoen, E. B. Coughlin, Macromolecules 2004, 37, 5123.

[60] R. R. Patel, R. Mohanraj, C. U. Pittman, J. Polym. Sci., Part B: Polym. Phys. 2006, 44, 234.

[61] W. A. Zhang, B. Fang, A. Walther, A. H. E. Muller, Macromolecules 2009, 42, 2563.

[62] J. Normatov, M. S. Silverstein, J. Polym. Sci. Pol. Chem. 2008, 46, 2357.

[63] E. H. Kim, S. W. Myoung, Y. G. Jung, U. Paik, Prog. Org. Coat. 2009, 64, 205

[64] G. Z. Li, H. Cho, L. C. Wang, H. Toghiani, C. U. Pittman, J. Polym. Sci. Pol. Chem. 2005, 43, 355.

[65] K. Koh, S. Sugiyama, T. Morinaga, K. Ohno, Y. Tsujii, T. Fukuda, M. Yamahiro, T. Iijima, H. Oikawa, K. Watanabe, T. Miyashita, Macromolecules 2005, 38, 1264.

[66] M. Mitsuishi, F. Zhao, Y. Kim, A. Watanabe, T. Miyashita, Chem. Mater. 2008, 20, 4310.

[67] E. Andrzejewska, A. Marcinkowska, K. Wegner, Polimery 2011, 56, 63.

[68] L. Liu, M. Tian, W. Zhang, L. O. Zhang, J. E. Mark, Polymer 2007, $48,3201$. 
[69] P. Majumdar, E. Lee, N. Gubbins, S. J. Stafslien, J. Daniels, C. J. Thorson, B. J. Chisholm, Polymer 2009, 50, 1124

[70] T. F. Baumann, T. V. Jones, T. Wilson, A. P. Saab, R. S. Maxwell, J. Polym. Sci. Pol. Chem. 2009, 47, 2589.

[71] H. S. Ryu, D. G. Kim, J. C. Lee, Polymer 2010, 51, 2296.

[72] A. Lee, J. D. Lichtenhan, Macromolecules 1998, 31, 4970.

[73] A. Lee, J. D. Lichtenhan, J. Appl. Polym. Sci. 1999, 73, 1993.

[74] L. Matejka, A. Strachota, J. Plestil, P. Whelan, M. Steinhart, M. Slouf, Macromolecules 2004, 37, 9449.

[75] G. M. Kim, H. Qin, X. Fang, F. C. Sun, P. T. Mather, J. Polym. Sci. Part B: Polym. Phys. 2003, 41, 3299.

[76] H. Z. Liu, S. X. Zheng, Macromol. Rapid Commun. 2005, 26, 196.

[77] S. Turri, M. Levi, Macromolecules 2005, 38, 5569.

[78] P. T. Knight, K. M. Lee, H. Qin, P. T. Mather, Biomacromolecules 2008, 9, 2458.

[79] M. Oaten, N. R. Choudhury, Macromolecules 2005, 38, 6392.

[80] A. K. Nanda, D. A. Wicks, S. A. Madbouly, J. U. Otaigbe, Macromolecules 2006, 39, 7037.
[81] J. C. Huang, C. B. He, Y. Xiao, K. Y. Mya, J. Dai, Y. P. Siow, Polymer 2003, 44, 4491.

[82] C. M. Leu, Y. T. Chang, K. H. Wei, Macromolecules 2003, 36, 9122.

[83] C. Dizman, S. Ates, L. Torun, Y. Yagci, Beilstein J. Org. Chem. $2010,6,56$

[84] M. Ak, B. Gacal, B. Kiskan, Y. Yagci, L. Toppare, Polymer 2008, 49, 2202.

[85] J. Zhang, R. W. Xu, D. S. Yu, Eur. Polym. J. 2007, 43, 743.

[86] H. M. Lin, S. Y. Wu, P. Y. Huang, C. F. Huang, S. W. Kuo, F. C. Chang, Macromol. Rapid Commun. 2006, 27, 1550.

[87] O. H. Zhang, H. He, K. Xi, X. Huang, X. H. Yu, X. D. Jia, Macromolecules 2011, 44, 550.

[88] M. Sanchez-Soto, S. Illescas, H. Milliman, D. A. Schiraldi, A. Arostegui, Macromol. Mater. Eng. 2010, 295, 846.

[89] G. Lligadas, J. C. Ronda, M. Galia, V. Cadiz, Biomacromolecules 2006, 7, 3521.

[90] S. L. Zhang, O. C. Zou, L. M. Wu, Macromol. Mater. Eng. 2006, 291, 895 . 